\title{
Integrated plan for the sustainable management of the Lagoon of Marano and Grado
}

\author{
Emiliano Ramieri, Environmental and Territorial Engineering Division, Thetis, emiliano.ramieri@thetis.it \\ Andrea Barbanti, Environmental and Territorial Engineering Division, Thetis, andrea.barbanti@thetis.it \\ Marco Picone, Environmental and Territorial Engineering Division, Thetis, marco.picone@thetis.it \\ Gianni Menchini, Special Commissioner of the Lagoon of Marano and Grado, segreteria@cdlaguna.regione.fvg.it \\ Enrico Bressan, Special Commissioner of the Lagoon of Marano and Grado, e.bressan@cdlaguna.regione.fvg.it \\ Elisa Dal Forno, Special Commissioner of the Lagoon of Marano and Grado, e.dalforno@cdlaguna.regione.fvg.it
}

\begin{abstract}
The Lagoon of Marano and Grado has been experiencing some remarkable environmental impacts, which have affected the high-value natural ecosystem and consequently influenced relevant socio-economic aspects. One of the main problems relates to the diffuse contamination of soil and groundwater in the mainland, as well as sediments in rivers and in the lagoon itself. The need to ensure safe navigation conditions in the lagoon and in the Corno River serving Porto Nogaro harbour is another critical emergency. Other environmental issues of concern are: loss of morphological diversity, watershed basins' pollution loads and protection of lagoon habitats. Due to the emergency situation, a Special Commissioner has been appointed by the national government to proceed with the resolution of the most critical problems. A specific "Operational Plan of interventions" was therefore elaborated in 2009. Approaching problems and solutions in an integrated way, the Plan represents one of the tools for the sustainable development of the lagoon. It strongly supports the adoption of adaptive management, foreseeing the periodical updating and improvement of objectives, strategies and interventions. The Plan also identifies the need for coordination among institutions and involvement of stakeholders as key elements for the implementation of adaptive management.
\end{abstract}

Keywords: coastal lagoon, Marano and Grado, environmental risk, contamination, integrated plan, adaptive management

\section{The Lagoon of Marano and Grado}

The Lagoon of Marano and Grado, located in the Northern Adriatic Sea (Figure 1), is a 160 $\mathrm{km}^{2}$ coastal lagoon, entirely classified as a Natura 2000 site according to Directive $92 / 43 /$ CEE. The lagoon system is delimited by the rivers Isonzo (east) and Tagliamento (west), and is separated from the Adriatic Sea by six barrier islands (1.6 to $6 \mathrm{~km}$ long, for a total length of $20 \mathrm{~km} ; 1-2 \mathrm{~km}$ wide). The six inlets subdivide the lagoon into as much hydraulic sub-basins; form west to east: Marano $\left(50.6 \mathrm{~km}^{2}-32.1 \%\right)$, S. Andrea $\left(21.5 \mathrm{~km}^{2}-\right.$ 13.7\%), Porto Buso (35.6 km² - 22.6\%), Morgo (3.0 km² - $1.9 \%)$, Grado (33.1 km² - $21.0 \%)$ and Primero (13.7 $\mathrm{km}^{2}-8.7 \%$ ) (ARPA-FVG, 2006). The drainage basin of the lagoon covers an area of about $1,880 \mathrm{~km}^{2}$, and delivers to the lagoon remarkable nutrients and pollutant loads (average freshwater flow to the lagoon is about $84 \mathrm{~m}^{3} / \mathrm{sec}$; ARPA-FVG, 2006). Main rivers flowing into the lagoon are the Stella River, particularly important for its estuarine habitats, the Cormor River, and the Corno River, that receives the water of the Aussa River before entering the lagoon. 
The lagoon is characterised by a relevant variety of morphologies (coastal areas, barrier islands, sandbanks, salt marshes, intertidal flats, tidal creeks, sub-tidal flats, canals, lagoon inlets) whose characteristics are strictly related to the tidal regime; average tidal range is about $65 \mathrm{~cm}$; maximum tidal range is about $105 \mathrm{~cm}$. In the last decades (particularly in the period 1954-1990) salt marshes surface has experienced remarkable decrease (Fontolan et al., 2009), particularly relevant in the central-western areas (i.e. S. Andrea, Grado and Porto Buso sub-basins), due to relative sea level rise, erosive processes and land reclamation. Main salt marshes are presently located in the area between Marano and S. Andrea subbasins (western) and in Morgo sub-basin (eastern). Fringing marshes are also located in the inner parts of the Marano sub-basin.

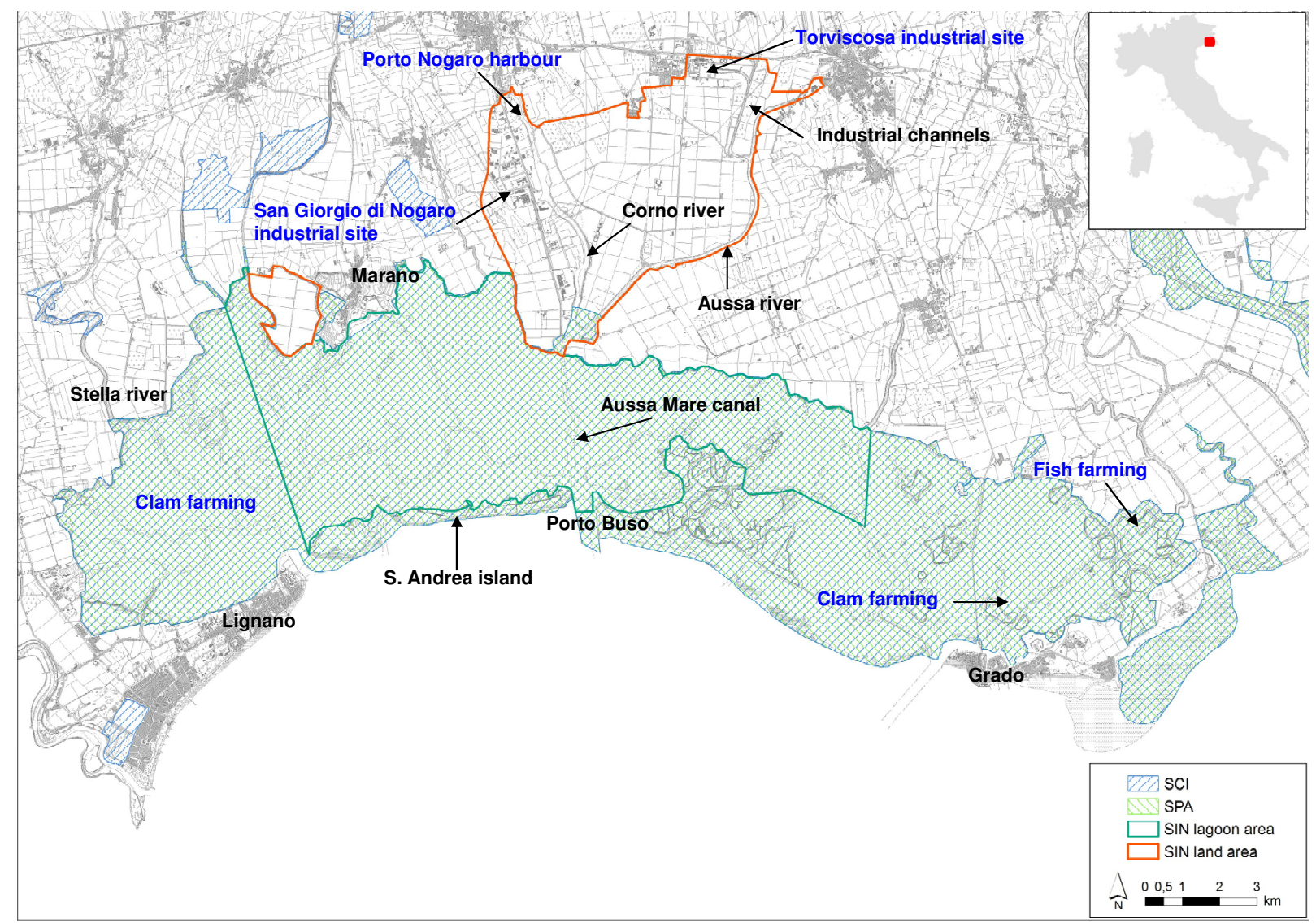

Figure 1 Main geographical features of the lagoon of Marano and Grado $(\mathrm{SCl}=$ Site of Community Importance, UE Directive 92/43; SPA = Special Protection Area, UE Directive 79/409)

More in general the whole lagoon morphology has been influenced by human activities, in particular in relation to: the construction of the breakwaters of Lignano, Porto Buso and Grado inlets; the creation of the commercial harbour of Porto Nogaro along the Corno river and the excavation (up to $7.5 \mathrm{~m}$ ) of the same river and the connected lagoon canal (Aussa Mare) for navigation reasons; the interventions of stabilisation of the barrier islands; the construction of docks and marinas for pleasure boating.

The lagoon canals form a $100 \mathrm{~km}$ network, partly navigable, connecting the lagoon to the Northern Adriatic Sea through the main inlets (Lignano, Porto Buso and Grado ones). The Aussa Mare canal is the main waterway and connects the Porto Buso inlet to the CornoAussa mouth. The Corno River reaches the harbour of Porto Nogaro and the close industrial 
area on the mainland (San Giorgio di Nogaro), while the Aussa River connects the lagoon to the industrial channels (Banduzzi and Banduzzi Nord) and therefore the industrial area of Torviscosa. Another potentially relevant waterway is the "Litoranea Veneta" that crosses the lagoon in the longitudinal direction. However, this waterway would require remarkable dredging interventions to re-establish good navigation conditions.

Besides its natural significance, in particular for wetland habitants and nesting and wintering birds (Regione Friuli Venezia Giulia et al., 2008), the lagoon and the neighbouring mainland territory host important socio-economic activities, including: the two industrial sites of San Giorgio di Nogaro and Torviscosa on the mainland; the commercial harbour of Porto Nogaro and the related water-borne transportation along the Aussa Mare canal - Corno river; fishing, fish farming and clam farming in the lagoon; tourism, in particular beach tourism in Lignano Sabbiadoro and Grado littorals; pleasure boating and other recreational activities, mainly in the lagoon, inner canals and rivers; agriculture in the drainage basin. The whole number of people living in the Plan's area of interventions is about 83,200, distributed in 15 small municipalities. Only two of them (Cervignano and Latisana) have more than 10,000 inhabitants.

\section{Environmental and socio-economic emergencies}

The lagoon of Marano and Grado has been experiencing some remarkable environmental impacts which have affected the high-value natural ecosystem and consequently influenced relevant socio-economic aspects. One of the main problems relates to the diffuse contamination of soil and groundwater in some industrial areas of the mainland, as well as sediments in industrial channels, rivers and the lagoon itself. For these reasons part of the lagoon and of the near by mainland have been included since 2003 in the Contaminated Sites of National Relevance (SIN) list.

The main source of concern is related to the Torviscosa industrial site, still in operation, that represents the highest source of chemical stress for the environment. The contamination is quite diffused throughout the site and regards soils (manly the upper meter) and particularly groundwater (Menchini et al., 2009). Moreover, about $220.000 \mathrm{~m}^{3}$ of wastes (fly ashes, pyrite ashes, toluene and benzoic pitch, barks, etc.) are located in different areas. The main chemical of concern is mercury $(\mathrm{Hg})$, while the occurrence of other contaminants as other heavy metals ( $\mathrm{Cd}, \mathrm{Zn}, \mathrm{As}, \mathrm{Pb}, \mathrm{Cu}$ ) polychlorinated dibenzodioxins (PCDDs) and furans (PCDFs), hydrocarbons, polycyclic aromatic hydrocarbons (PAHs) and aromatic hydrocarbons, is closely related to the location of the different chemical productions that took place in the industrial site. Effluents and chemicals discharged (in particular due to the chloralkali plant that became operative in 1949 and that is presently not-operative) into the industrial channels caused a remarkable $\mathrm{Hg}$ contamination of their sediments, as well as of the sediments of the connected Aussa River. The other industrial area of San Giorgio di Nogaro, partly still under investigation, is characterised by a less critical environmental situation. Contamination appears to be less diffuse and localised in specific hot-spots. Soil contamination is mainly related to the location of waste disposal and industrial processes and due in particular to heavy metals $(\mathrm{Hg}, \mathrm{Cr}, \mathrm{As}, \mathrm{Pb}, \mathrm{Zn})$, and to a lesser extent to hydrocarbons and polychlorinated biphenyls (PCB). Main chemicals of concern for groundwater are heavy metals, carcinogenic chlorinated aliphatic, hydrocarbons and benzene. Similarly, the 
environmental quality of the Corno River looks better than the Aussa one, both in terms of contaminants and measured concentrations.

The Aussa river, and to a lesser extent the Corno river, have contributed to the $\mathrm{Hg}$ contamination of the lagoon sediments (Piani et al., 2005), particularly in the central area (Porto Buso sub-basin). The occurrence of $\mathrm{Hg}$ in the lagoon is however also linked to the historical terrigenous supply of the river Isonzo, that contributes to the enrichment of $\mathrm{Hg}$ (cinnabar) especially in the eastern area of the lagoon (close to Grado) and to a lesser extent in the western area (Brambati, 2001; Covelli et al., 2001; Covelli et al., 2008). Sediment contamination and bioaccumulation of $\mathrm{Hg}$ in tissues of different edible species of molluscs, fishes and crustaceans increase also the concern about ecosystem and human health risk linked to the exposure to $\mathrm{Hg}$, highlighting the urgency for a remediation plan for contaminated sediments, aiming in particular to the improvement of habitat conditions and sustainable management of fisheries (including clam and fish farming) (Ceschia et al., 1982; Brambati, 2001).

The need to ensure safe navigation conditions in the lagoon, and in particular in the Corno River and canals respectively serving Porto Nogaro harbour and marinas, is another critical emergency. The required interventions are vital to support the economic activities of the port along the Corno, but also more in general to still enable the navigation along the whole lagoon network. The volume to be dredged is remarkably large (estimated in about $3,009,000 \mathrm{~m}^{3}$ ) and partly contaminated (about $27.7 \%$ for the whole area; $42.7 \%$ for the Aussa river). This implies the need for the proper management, disposal and reuse of the excavated materials in compliance with the specific rules defined for the lagoon of Marano and Grado. The previously described ones definitely represent the most urgent problems to be solved; other issues of concern are:

- The erosion and loss of morphological diversity of the lagoon (Regione Friuli Venezia Giulia, 2008), implying in particular: loss of salt marshes and intertidal flats, erosion and deepening of sub-tidal flats, siltation of canals, erosion of barrier islands. These modifications tend to simplify the morphological structure of the lagoon and to gradually transform the lagoon into a marine bay;

- The need for the protection of the high-value natural habitats of the lagoon, in particular seagrass meadows, salt marshes, inter-tidal flats habitats, freshwater habitats (Regione Friuli Venezia Giulia, 2008);

- The high nutrient (especially $\mathrm{N}$ ), and to a minor extent herbicide, loads coming from the drainage basin, in particular generated by agricultural and zootechnical non-point sources (Autorità di Bacino dell'Adige e dell'Alto Adriatico, 2010). Although the lagoon ecosystem is generally characterised by a mesotrophic equilibrium (it did not experience remarkable micro/macro algae blooms and anoxic crises in recent years), average $\mathrm{N}$ concentration is rather high $(900 \mu \mathrm{g} / \mathrm{l}$ on the eastern area and $2000 \mu \mathrm{g} / \mathrm{l}$ on the western area of the lagoon), in particular near major river mouths (about a $2500 \div 3000 \mu \mathrm{g} / \mathrm{l}$ ) (ARPA-FVG, 2006), indeed deserving particular attention;

- The sustainable management of fishing activities, including fish and clam farming, in particularly in relation to the: environmental quality of the lagoon, $\mathrm{Hg}$ contamination of sediments, maintenance of fish and clam stocks, impacts of fishing activities on the lagoon habitats, maintenance or improvement of fishermen incomes. 
The environmental problems of the lagoon territory are mutually interrelated and linked to socio-economic aspects; the adoption of a holistic approach in the lagoon management and the elaboration of an integrated plan have therefore become necessary.

\section{Institutional aspects}

Up to 2001, the management of the lagoon territory was entrusted to the Venice Water Authority, a specific institution directly related to the Italian Ministry of Infrastructure and Transportation. D.Lgs. 265/2001 decentralised the competences on the lagoon from the central State to the Regional Authority of Friuli Venezia Giulia. Due to the environmental and socio-economic problems previously described, and in particular those implying risks for the human health and the ecosystem, on May 2002 the Italian Prime Minister (D.P.C.M. $3^{\text {rd }}$ of May 2002) declared the status of emergency for the Lagoon of Marano and Grado. This particular status enables to issue legislative acts and define procedures specifically oriented to the resolution of the emergency, to be of course coordinated with the ordinary legislation, as well as to rapidly activate the necessary resources, including economic ones. The Italian Civil Protection, directly depending on the national government, is the body responsible for the management of the emergency situations.

Consequently, on June 2002, a Special Commissioner of the lagoon of Marano and Grado was appointed by the national government in order to proceed with the resolution of the emergency and to manage the lagoon system. Successive legislative acts have specifically identified the responsibilities, competences and powers of the Commissioner, in relation to the following main issues: environmental remediation of contaminated soil and groundwater; re-establishment of safe navigation conditions in the lagoon, in particular implying sediment dredging and proper disposal or reuse of dredged materials; requalification of the lagoon ecosystem, in particular in relation to sediment contamination and water quality; protection of high-value lagoon habitats; morphological restoration of the lagoon; reduction of pollutant loads from the drainage basin; knowledge integration and environmental monitoring. The Commissioner is supported by an internal team of administrative and technical experts. It can also rely on the technical support of public institutions and bodies including: the Venice Water Authority, the Civil Protection, the National Institution for the Protection of the Environment (ISPRA), the Regional Institution for the Protection of the Environment (ARPA FVG), the Regional Water Basin Authority, the National Research Council, and the Universities. The cooperation and coordination with ordinary administration of the territory is ensured by two specific committees that foresee the participation of the main national, regional and local authorities and institutions, i.e.: (i) the Technical Scientific Committee (nine members) that has the responsibility of evaluating and approving the plans, studies and projects implemented by the Commissioner; (ii) the Technical Advisory Committee (three members) that guarantees the administrative and juridical support to the Commissioner's activities.

On 2009 the Commissioner decided to elaborate a specific "Operational Plan of interventions for the Lagoon of Marano and Grado" to deal with the emergency situation and start an integrated and medium-term (10 years) management process of the coastal system. In relations to the competences entrusted to the Commissioner as well as the main environmental concerns, the Plan's area of intervention extends beyond the specific limit of the lagoon ecosystem. Indeed it also includes on the mainland the whole area being part of 
the SIN (about $42 \mathrm{~km}^{2}$ ) and a $4 \mathrm{~km}$ wide strip $\left(363 \mathrm{~km}^{2}\right.$ - partly covering the territory of 15 municipalities) on which the Commissioner has specific competences and powers. Conceptually the Plan also considers the whole drainage basin, because of the pollutant loads discharged into the lagoon, and the facing marine area because of the vital water exchanges and the related morphological processes.

\section{Methods}

The Plan was elaborated by a multidisciplinary team of experts that worked in close cooperation with the decision maker level, i.e. the Special Commissioner supported by its technical staff. The development process did not envisage a proper participatory phase; the Plan indeed represents an operational tool of the Commissioner's action. However, the Plan identifies some interventions and actions whose realisation requires also the operative competence of other institutions; their involvement in the Plan drafting process was therefore a necessary step that foresaw a continuous discussion within the Technical Scientific Committee and the Technical Advisory Committee, involving stake-holders representing national, regional and local institutions, as well as the organisation of public meetings.

The Plan elaboration was based on an integrated and holistic approach that enabled to: define a comprehensive framework of interventions, optimise the synergies between the planned interventions, reduce as much as possible negative feedbacks, positively address the overall effect of the Plan on the lagoon system. The approach adopted in the Plan can be summarised as: description of main problems by means of an integrated socio-economic and environmental analysis; definition of objectives and strategies to be addressed for the resolution of the emergency in the Lagoon of Marano e Grado; identification of interventions to be implemented to reach defined objectives and strategies; definition of an integrated view of required economic resources; chronology planning considering short-term (resolution of critical urgencies) and medium-long term perspectives (progressive and continuous system management). The Plan is a flexible and dynamic tool, since it will undergo periodical (yearly) updating, taking in consideration newly available data and information on the lagoon system, future realised interventions and still existing emergencies. In this perspective, the close interaction among monitoring, experimentation and planning is highly recommended by the same Plan.

\section{The Operational Plan}

The objectives, strategies and interventions of the Plan deal with eight principal issues, directly related to the responsibilities and competences entrusted to the Commissioner: (a) remediation of contaminated soil and groundwater, (b) interventions for the re-establishment of safe navigation conditions in the lagoon, (c) requalification of the lagoon ecosystem, (d) morphological requalification of the lagoon, (e) reduction of pollutant loads from the drainage basin, (f) completion of knowledge gaps and integrated monitoring, (g) sustainable development and adaptive management, $(\mathrm{h})$ communication activities.

Because of the broad themes of interest, the Plan is rather complex and includes many guidelines and interventions mutually interrelated. The principal ones are summarised in the table of Figure 2. The same table also indicates: whether the realisation of such interventions implies only the competence of the Commissioner (SC) or even/exclusively the competence of other subjects $(\mathrm{SC}+\mathrm{OS} / \mathrm{OS})$; the priority of the planned interventions $(\mathrm{VH}=$ very high, $\mathrm{H}=$ 
high, $M=$ medium, $L=$ low); the positive effects of the specific intervention on the other issues addressed in the Plan (+++ = high, $++=$ medium, $+=$ low).

\begin{tabular}{|c|c|c|c|c|c|}
\hline & & Main strategies and interventions & Priority & $\begin{array}{l}\text { Compete } \\
\text { nce }\end{array}$ & $\begin{array}{l}\text { Effect on other } \\
\text { issues }\end{array}$ \\
\hline \multirow{4}{*}{ (a) } & 1 & $\begin{array}{l}\text { Environmental remediation of the Torviscosa industrial } \\
\text { site and surrounding areas }\end{array}$ & $\mathrm{VH}$ & $\mathrm{SC}+\mathrm{OS}$ & $\begin{array}{l}(\mathrm{a} 4)+++;(\mathrm{c})++ \\
(\mathrm{g} 4)+++\end{array}$ \\
\hline & 2 & $\begin{array}{l}\text { Environmental remediation of the industrial channels } \\
\text { (Banduzzi e Banduzzi Nord) }\end{array}$ & VH & SC & $\begin{array}{l}(\mathrm{b} 1)+;(\mathrm{c})+++;(\mathrm{e}) \\
++\end{array}$ \\
\hline & 3 & $\begin{array}{l}\text { Completion of environmental investigation and } \\
\text { remediation of other SIN contaminated areas }\end{array}$ & $\mathrm{H}$ & OS & $\begin{array}{l}(\mathrm{a} 4)+++;(\mathrm{c})+;(\mathrm{f} 1) \\
+++;(\mathrm{g} 4)+++\end{array}$ \\
\hline & 4 & $\begin{array}{l}\text { Progressive re-use and development of suitable SIN } \\
\text { areas and re-definition of the SIN limits }\end{array}$ & M & OS & (g2) ++; (g4) +++ \\
\hline \multirow{3}{*}{ (b) } & 1 & $\begin{array}{l}\text { Excavation of navigable rivers and canals ( } 3 \text { steps); } \\
\text { priority to urgent interventions (Corno river) }\end{array}$ & $\mathrm{VH} / \mathrm{M} / \mathrm{L}$ & SC & $\begin{array}{l}\text { (c2) }+++;(\mathrm{d} 1)+++ \\
\text { (d3) }++;(\mathrm{g} 4)+++\end{array}$ \\
\hline & 2 & Maintenance Plan of excavated canals & M & SC & $\begin{array}{l}(c 2)+;(d 1)+++ \\
(g 2,4)+++\end{array}$ \\
\hline & 3 & $\begin{array}{l}\text { Re-use and proper disposal of dredged sediments, } \\
\text { according to their contamination levels }\end{array}$ & $\mathrm{H} / \mathrm{M} / \mathrm{L}$ & SC & $\begin{array}{l}(\mathrm{c})+;(\mathrm{d} 1)+++;(\mathrm{d} 2) \\
++;(\mathrm{g} 4)++\end{array}$ \\
\hline \multirow{4}{*}{ (c) } & 1 & $\begin{array}{l}\text { Achievement of objectives defined by the EU Water } \\
\text { Framework Directive }(2000 / 60) \text { for the lagoon }\end{array}$ & M & OS & $\begin{array}{l}(\mathrm{c} 3)++;(\mathrm{c} 4)++ \\
(\mathrm{f} 1) ;(\mathrm{g} 2)+++\end{array}$ \\
\hline & 2 & $\begin{array}{l}\text { Interventions on contaminated sediments in the lagoon } \\
\text { and rivers (Aussa and Corno) }\end{array}$ & $\mathrm{H} / \mathrm{M} / \mathrm{L}$ & SC & $\begin{array}{l}(\mathrm{b} 1)++;(\mathrm{c} 1)+++ \\
(\mathrm{c} 4)+++,(\mathrm{g} 4)+++\end{array}$ \\
\hline & 3 & $\begin{array}{l}\text { Protection of lagoon habitats (seagrass, salt marshes, } \\
\text { intertidal flats, freshwater habitats) }\end{array}$ & $\mathrm{H}$ & $\mathrm{SC}+\mathrm{OS}$ & $\begin{array}{l}\text { (c1) }++;(d 1)+++ \\
\text { (g2) }+++;(g 4)+++\end{array}$ \\
\hline & 4 & $\begin{array}{l}\text { Sustainable planning and management of fishing } \\
\text { activities in the lagoon, in particular clam farming }\end{array}$ & M & OS & (g2) +++; (g4) +++ \\
\hline \multirow{3}{*}{ (d) } & 1 & $\begin{array}{l}\text { Interventions for the reduction of the lagoon erosion } \\
\text { and the restoration of salt marshes, flats and canals }\end{array}$ & $\mathrm{H} / \mathrm{M}$ & $\mathrm{SC}+\mathrm{OS}$ & $\begin{array}{l}(\mathrm{b} 1,2)++;(\mathrm{c} 1,3,4) \\
+++;(\mathrm{g} 2)+++\end{array}$ \\
\hline & 2 & Restoration of freshwater habitats on the lagoon border & $\mathrm{L}$ & $\mathrm{SC}+\mathrm{OS}$ & $\begin{array}{l}(\mathrm{c} 1,3)+++;(\mathrm{e} 2) \\
++;(\mathrm{g} 2)++\end{array}$ \\
\hline & 3 & $\begin{array}{l}\text { Nourishment of sand banks of littoral islands (in } \\
\text { particular S. Andrea) }\end{array}$ & $\mathrm{H}$ & $\mathrm{SC}+\mathrm{OS}$ & $(\mathrm{c} 3)++;(g 2,4)++$ \\
\hline \multirow{2}{*}{ (e) } & 1 & $\begin{array}{l}\text { Continuation of the reduction of nutrient and herbicide } \\
\text { loads, in particular acting on non-point sources }\end{array}$ & L & OS & $(c 1)+++;(c 4)+$ \\
\hline & 2 & $\begin{array}{l}\text { Promotion of interventions for the reduction of residual } \\
\text { loads, i.e. phyto-depuration in estuarine areas }\end{array}$ & $\mathrm{L}$ & $\mathrm{SC}+\mathrm{OS}$ & $\begin{array}{l}(c 1)+++;(c 4)+; \\
(d 2)+++\end{array}$ \\
\hline$(f)$ & 1 & $\begin{array}{l}\text { Completion of knowledge gaps, integrated monitoring } \\
\text { network and shared models, GIS and database }\end{array}$ & $\mathrm{H}$ & $\mathrm{SC}+\mathrm{OS}$ & $(g$ 1, 2, 3) +++ \\
\hline \multirow{4}{*}{ (g) } & 1 & $\begin{array}{l}\text { Shift from the emergency to the ordinary management } \\
\text { of the Lagoon of Marano and Grado }\end{array}$ & $\mathrm{H}$ & $\mathrm{SC}+\mathrm{OS}$ & Linked to all points \\
\hline & 2 & Development of an adaptive management Plan & $\mathrm{H}$ & $\mathrm{OS}+(\mathrm{SC})$ & Linked to all points \\
\hline & 3 & $\begin{array}{l}\text { Promotion of coordination and cooperation among } \\
\text { different institutions, and participation of stake-holders }\end{array}$ & $\mathrm{H}$ & $\mathrm{OS}+(\mathrm{SC})$ & Linked to all points \\
\hline & 4 & $\begin{array}{l}\text { Diversification of economic activities and promotion of } \\
\text { sustainable ones }\end{array}$ & $\mathrm{H}$ & $\mathrm{SC}+\mathrm{OS}$ & Linked to all points \\
\hline (h) & 1 & $\begin{array}{l}\text { Communication of Commissioner's activity to stake- } \\
\text { holders and citizens }\end{array}$ & $\mathrm{H}$ & SC & Linked to all points \\
\hline
\end{tabular}

Fig. 2. Summary of principal strategies and interventions foreseen by the Operational Plan 
Highest priority is given to the first two issues because of their interrelation with critical environmental and socio-economic aspects. For the first issue, specific focus is on the industrial area of Torviscosa, both because of the high contamination of soil, groundwater and industrial channel sediments and the direct responsibility of the Commissioner on this area. The Plan foresees the progressive remediation of the whole industrial site (including industrial plants, old landfills and bare areas) and the neighbouring areas (including the industrial channels, agricultural areas, old Confined Disposal Facilities - CDF's located along the Aussa River) according to a specific environmental remediation project elaborated by the Commissioner (Menchini et al., 2009) and recently approved by the Italian Ministry of the Environment. Its realisation will also contribute to stop contaminant transfer (in particular $\mathrm{Hg}$ ) to the lagoon. For the other industrial area of San Giorgio di Nogaro (not within the direct responsibility of the Commissioner) the Plan foresees the completion of the environmental investigation and the progressive remediation of contaminated areas. For both industrial settlements, and more in general for the whole SIN, the final goal is not only the resolution of the remarkable environmental problems, but also the future use or reuse of these areas. The Plan even aims to possibly redefine the limits of the SIN in order to contribute to the further development and the socio-economic revitalization of the overall territory of the lagoon of Marano and Grado.

Similarly, the excavation of sediments from the lagoon canals and the main rivers is principally finalised to the re-establishment of safe navigation conditions and to support the related socio-economic activities (port, water transportation, pleasure boating, tourism); at the same time it will contribute to the environmental requalification of the lagoon by the removal of contaminated material. The highest priority is the on-going excavation (up to 7.5 $\mathrm{m}$ ) of the Corno River $\left(168,000 \mathrm{~m}^{3}\right)$ in order to remove the physical limitation to the operation of the Porto Nogaro harbour. A more extensive series of interventions is needed to reestablish safe navigation conditions in the whole lagoon, to be realised in three steps of priority according to the Plan (step $1-637,000 \mathrm{~m}^{3}$; step $2-400,000 \mathrm{~m}^{3}$; step $3-1,265,000$ $\mathrm{m}^{3}$ ). Dredging activities will generate a large amount of materials to be properly managed; the Plan bases sediment management and disposal on the following sustainable criteria, i.e. maximisation of the local reuse of "good quality" sediments in particular to face the erosion and restore typical lagoon morphological structures; design of proper solutions for the disposal of contaminated sediments to be based on health and ecosystem risk analysis; testing of innovative technologies to reduce sediment contamination and improve reuse opportunities; minimisation of material transfer to disposal sites outside the lagoon.

Besides the urgent interventions previously described to be immediately initiated, the Plan indentifies a further number of relevant actions to be started in the short time (1-2 years). These include:

- Interventions on contaminated sediments of the lagoon (canals and tidal flats) and rivers, particularly relevant because of the implications for the general environmental quality of the ecosystem and the fishing activities. Priority is on more contaminated areas (i.e. the industrial channels, the Aussa River and the Aussa Mare canal) as well as on those areas that can determine a greater potential risk to the human and

\footnotetext{
Once the emergency will be solved, further sediments to be managed will be generated by the periodical maintenance of the canals, in order to remove the yearly siltation (very preliminary estimation of about 10 to $30 \mathrm{~cm}$ ).
} 
ecosystem, including clam and fish farming zones or the portions of the lagoon that are affected by higher sediment resuspension due to wind and water traffic.

- Morphological interventions and related habitat restoration on most degraded areas, i.e. protection and restoration of salt marshes; protection of tidal flats located along the main canals in order to improve the morphological separation among the two elements; improvement of the quality and functions of the river mouth habitats; protection and reinforcement of the $\mathrm{S}$. Andrea barrier island. These interventions will require about 1.7 million $\mathrm{m}^{3}$ of sediments, thus representing a remarkable opportunity for the reuse of dredged materials for navigation purposes;

- The implementation of sustainable fishing modalities, in particular continuing the transition from unregulated clam harvesting, presently rather limited, to clam farming in specifically identified and managed areas. The Plan also recommends the design and adoption of an integrated plan for the overall management of fisheries resources in the Lagoon of Marano and Grado;

- Completion of the existing knowledge gaps and support to data and knowledge sharing, in particular through the realisation of an integrated environmental monitoring system and an integrated network of shared tools including databases, web-based GIS and models.

Following the Plan elaboration, some important interventions started in 2010 , in particularly in relation to the remediation of contaminated soil and groundwater in the Torviscosa industrial area, dredging of the Corno River and some silted lagoon canals, management of removed sediments and knowledge integration and sharing.

\section{Conclusions}

The "Operational Plan of interventions for the Lagoon of Marano and Grado" is an articulated example of an integrated plan dealing with a complex coastal area and a large number of interlinked environmental and socio-economic issues. Planned interventions have been principally designed to find solutions to the main environmental emergencies, however also aiming to generate direct and indirect positive effects on local economic activities (in particular on fishing, sustainable tourism, recreational activities, port activities, post-industrial development), thus contributing to maintain a good diversification of the productive system.

Some lessons and indications can be drawn for the future management of the lagoon of Marano and Grado and of similar coastal systems as well. The final aim is to move from the extraordinary management situation determined by the declaration of the emergency status to an ordinary, integrated and long-term management of the lagoon territory. This has to be based on adaptive planning, monitoring and management. Indeed the Plan represents a first step of the adaptive process; among the planned interventions the Plan foresees its periodical updating and the continuous review and improvement of objectives, strategies and interventions. A set of knowledge tools have been identified by the Plan to support the adaptive process, including periodical reports on the state of the environment, sustainability indicators, ecosystem service analysis and shared knowledge instruments.

Some key elements will have to be strengthen to fully support the adaptive integrated management: (i) the real coordination among the various national, regional and local public authorities that are entrusted with institutional responsibilities and technical competences on 
the lagoon; (ii) the involvement of stakeholders (including citizens) in the design of the lagoon future; (iii) the monitoring process of the Plan's performance and the communication of the obtained results; (iv) the adoption of a long term perspective that take in considerations the impacts of global changes (loss of biodiversity, climate change, loss of ecosystem services, etc.) on the lagoon.

\section{References}

ARPA Friuli Venezia Giulia (Regional Environmental Protection Agency), 2006. Report on the state of the environment, 2005 (In Italian; Rapporto sullo stato dell'ambiente, aggiornamento 2005).

Autorità di Bacino dell'Adige e dell'Alto Adriatico (Water Basin Authorities of the Adige River and Northern Adriatic Sea), 2010. River basin management plan of the Oriental Alps. Drainage basin of the Lagoon of Marano and Grado (In Italian; Piano di gestione dei bacini idrografici delle Alpi Orientali. Bacini dei tributari della Laguna di Marano e Grado). http://www.alpiorientali.it

Brambati A., 2001. Coastal sediments and biota as indicators of $\mathrm{Hg}$ contamination in the Marano and Grado Lagoons. RMZ - Materials and Geoenvironments 48: 165-171.

Ceschia G., Giorgetti G. and Simonutti T, 1982. Lagoons of Grado. Researches on environmental factors of some lagoons and sanitary condition or reared fish (In Italian; Valli da pesca della Laguna di Grado indagine sulle condizioni ambientali di alcune valli da pesca e sullo stato sanitario delle specie ittiche presenti). Atti del Museo Friulano di Storia Naturale, 4: 185-198.

Covelli S., Faganeli J., Horvat M. and Brambati A., 2001. Mercury contamination of coastal sediments as the results of long-term cinnabar activity (Gulf of Trieste, Northern Adriatic Sea). Applied Geochemistry 16: 541-558.

Covelli S., Faganeli J., De Vittor C., Predonzani S., Acquavita A., and Horvat M., 2008. Benthic fluxes of mercury species in a lagoon environment (Grado Lagoon, Northern Adriatic Sea, Italy). Applied Geochemistry 23: 529-546.

Fontolan G., Pillon S., and Facchin G., 2009. Multidecadal salt marsh evolution in the northern Adriatic lagoons, Italy: erosional style and morphological adaptation to transgressive forcing (In Italian; Trasformazioni territoriali ed aspetti fisici di adattamento dell'ecosistema naturale delle lagune di Grado e Marano conseguenti all'innalzamento del livello del mare). VECTOR - II Yearly Workshop (Roma, 25-26 February 2009), http://vector.conismamibi.it/files/ll\%20workshop/orali/Fontolan.pdf

Menchini G., Amoroso C., Barbanti A., Ramieri E., Melli F., Lopez y Royo F., Molinari L., Simeoni P. and Bressan E., 2009. The remediation project of the industrial area of Torviscosa (In Italian; II progetto di bonifica del sito industriale di Torviscosa). Rassegna Tecnica del Friuli Venezia Giulia, Anno LX, Novembre - Dicembre 2009.

Piani R., Covelli S. and Biester H, 2005. Mercury contamination in Marano Lagoon (Northern Adriatic Sea, Italy): source identification by analyses of $\mathrm{Hg}$ phases. Applied Geochemistry 20: 1546-1559. 
Regione Friuli Venezia Giulia (Regional Authority) et al., 2008. ANSER Project. The ANSER project (Interreg IIIA Adriatic Cross Border): evaluation of the ecologic role of wet areas in the stopover and wintering of water birds in the northern Adriatic Sea. http://www.anserproject.it/

Regione Friuli Venezia Giulia (Regional Authority), 2008. Management plan of the SCI/SPA IT3320037 Lagoon of Marano and Grado. Draft version (In Italian; Piano di gestione del SIC/ZPS IT3320037 Laguna di Marano e Grado. Bozza definitiva). . http://www.regione.fvg.it/rafvg/territorioambiente/dettaglio.act?dir=/rafvg/cms/RAFVG/AT9/A RG5/FOGLIA39/

\section{Acknowledgements}

The authors gratefully acknowledge Prof. Chiara Mio e Davide Da Pieve of the University Ca' Foscari of Venice for the socio-economic analysis of the lagoon territory and their contribution the Plan development. 